\title{
AÇÃO PIANÍSTICA E COODENAÇÃO MOTORA: PROCESSOS DE FEEDBACK E APLICAÇÃO DE MÉTODOS DE ANÁLISE
}

\author{
Maria Bernardete Castelan Póvoas²; Daniel da Silva ${ }^{3}$
}

Palavras-chave: ação pianística; coordenação motora; feedback; método de análise.

Resumo: Esta investigação faz parte da pesquisa "Ação pianística e coordenação motora: relações interdisciplinares". Discorre-se sobre como ocorre o fornecimento de feedback durante a aprendizagem de habilidades motora associando-se argumentos levantados com a aprática pianística. Encontram-se descritos alguns métodos de análise advindos da área de biomecânica, considerando-se seu emprego na avaliação do trabalho músicoinstrumental.

\section{Introdução}

No contexto da prática instrumental, a compreensão dos aspectos envolvidos na produção do movimento é de grande importância para que se possa criar estratégias eficientes de estudo. Os movimentos utilizados na ação pianística envolvem uma combinação de diferentes segmentos do corpo, sendo que a utilização do movimento mais eficiente para se atingir determinado resultado musical exige que se tenha conhecimentos acerca de sua estrutura, o que deixa claro a importância da interdisciplinaridade para a atividade instrumental. "Estas ciências [como a Anatomia e a Fisiologia] deveriam ser os pilares de sustentação do processo de ensino-aprendizagem dos instrumentos musicais". (KAPLAN, 1987, p.13). Todos os movimentos participantes na ação instrumental encontram-se interligados em complexas estruturas anatômicas, sendo que somente através de um completo domínio dessas estruturas pode-se atingir um alto nível de eficiência. "A execução instrumental requer habilidades altamente refinadas e um alto grau de conscientização corporal, para que se possa atingir uma realização ótima”. (CIARLINI e RAFAEL, 1994, p.32).

Para que uma habilidade seja executada com sucesso, é necessário que o indivíduo receba informações acerca de seu progresso nessa dada habilidade. A

\footnotetext{
${ }^{1}$ Projeto de Pesquisa CEART-UDESC.

${ }^{2}$ Orientadora, Professora do Departamento de Música - Centro de Artes - Florianópolis - SC.

${ }^{3}$ Acadêmico do Curso de Bacharelado em Piano - CEART/UDESC, bolsista de iniciação científica do PROBIC/UDESC.
} 
aquisição e a retenção das habilidades motoras ocorrem através do feedback, que são informações sensoriais fornecidas ao indivíduo durante ou após a execução de uma ação.

Os métodos de análise (ou medidas de processo) têm como foco principal o aperfeiçoamento de uma habilidade motora, através da observação, descrição e análise dos movimentos executados por indivíduos. É essencial que o pesquisador ou o grupo de pesquisa esteja informado a respeito da anatomia humana e princípios mecânicos, assim como acerca das habilidades motoras e padrões de movimento. Devido ao alto grau de variabilidade que a reprodução do movimento humano pode apresentar, a análise de um movimento em sua complexidade estrutural deve ser caracterizada por grande objetividade e confiabilidade. (Amadio et al., 2002). Em se tratando da ação pianística, é importante também conhecer não apenas a proposta do movimento, mas também sobre os fatores de desempenho (Rasch, 1991) inerentes a execução habilidosa deste movimento, tais como, força, fadiga, rapidez do movimento, flexibilidade, entre outros.

\section{Discussão}

\section{Tipos de feedback}

Durante ou após a execução de uma ação, informações sensoriais são fornecidas ao indivíduo, as quais denomina-se de feedback intrínseco (ou proprioceptivo) e feedback extrínseco (ou aumentado).

O feedback intrínseco é fornecido por meio dos órgãos sensoriais (como a audição e a visão) do próprio sujeito que realizou o movimento. De acordo com o nível de habilidade do executante, o feedback intrínseco pode fornecer um grande número de informações sobre o movimento realizado, tais como níveis de precisão, postura do corpo e dos membros envolvidos na ação, entre outras informações. Este tipo de feedback pode ajudar muito o músico durante a execução de uma peça, pois o auxilia na detecção e correção de erros cometidos após ou durante a conclusão do movimento. Nestes casos, o feedback intrínseco se torna mais efetivo em ações que envolvam movimentos lentos e voluntários, pois assim o executante pode fazer compensações durante a ação, o que em movimentos rápidos não acontece devido ao tempo de resposta não acompanhar o tempo de execução do movimento. (Piekarzievcz, 2004). Ressalta-se aqui a importância de que os movimentos devam ser pensados anteriormente à ação: "tornou-se evidente a necessidade de planejar o 
movimento antes da ação em função de resultados sonoros previamente estabelecidos, adequando-se movimentos corporais à resolução de aspectos musicais". (PÓVOAS, 1999, p.45). Quando a ação planejada não alcança sua meta, esta pode estar sendo prejudicada por algum erro no planejamento do movimento, tendo o feedback nesse caso uma função de detectar quais aspectos estão influenciando nesse desempenho.

O feedback extrínseco ou aumentado é fornecido ao indivíduo que executou o movimento a fim de informar-lhe a respeito de suas ações. Os meios mais comuns de fornecimento de feedback extrínseco são: (1) informações transmitidas por um professor sobre um movimento executado ou como executar corretamente uma habilidade motora, (2) demonstração através de uma gravação sonora ou áudiovisual do desempenho do executante. Esse tipo de feedback tem um papel importante no transcorrer do processo de aquisição de uma habilidade motora pois, além de trazer informações importantes ao progresso do indivíduo, tem propriedades motivacionais que trazem ao aprendiz estímulos para que continue desempenhando seu trabalho no transcorrer da prática.

É aconselhável que na transmissão do feedback extrínseco verbal sejam enumeradas prioridades nas informações, pois uma quantidade grande de informações poderá deixar o aluno confuso acerca do que é mais importante se ater naquele momento. Inicialmente, aconselha-se focar a atenção do aprendiz nos padrões mais fundamentais do movimento, direcionando a atenção dele para um ou dois aspectos de cada vez, pois, se o aluno aprender uma ação inadequadamente à prática ao início do seu processo de estudo, a fixação poderá se tornar tão forte que será difícil esquecer posteriormente esse padrão automatizado. Neste estágio normalmente os indivíduos não são capazes de detectar as características relevantes do movimento executado, assim como a origem de seus erros, embora tenham consciência de que não dominaram com destreza essas habilidades. Nesse contexto, o feedback intrínseco ainda não é suficiente para que o aluno tome as direções e regulações corretas inerentes do processo de coordenação motora. (Maggil, 2000). Para esses casos, é fundamental o papel do feedback extrínseco, que traz informações suplementares e reforça o feedback intrínseco.

Consciente da importância do entendimento das diferentes características do movimento, o professor pode selecionar e enfatizar primeiramente o padrão de movimento mais importante envolvido na ação e, depois que o aluno tenha dominado esse padrão, progressivamente fornecer feedback sobre outros aspectos 
do movimento. (Schmidt e Wrisberg, 2001). No caso da prática pianística, desde o início do estudo de uma peça ou de parte dela, deve-se estar bem informado sobre os passos do processo para aquisição de uma dada habilidade motora, e que este processo pode ocorrer de maneira lenta e gradativa, o que requer atenção permanente. Uma forma de se evitar que a tarefa de torne monótona e repetitiva é variar o tipo de estudo, assim como evitar a permanência ininterrupta durante um longo período de tempo em um mesmo trecho de uma peça.

O feedback quando dado após a execução de uma ação correta, é chamado de feedback de reforço. Este tem função de assegurar uma maior confiança na ação desempenhada e aumentar a probabilidade que esta ação será repetida em outra situação semelhante. Thorndike (1927) apud Schmidt e Wrisberg (2001, p. 277) diz que:

\footnotetext{
"Uma ação disparada por um estímulo e seguida por conseqüências prazerosas ou recompensadoras tende a se repetir quando o estímulo surgir novamente; uma ação que é seguida por conseqüências não prazerosas ou punitivas tende a não ser repetidas".
}

Esse reforço positivo pode ser transmitido tanto de forma verbal (por exemplo: "você está realizando muito bem aqueles stacattos de pulso") como de forma não verbal (por exemplo: "uma expressão facial de aprovação após o término de um trecho difícil"). A comunicação torna-se mais efetiva quando a mensagem é transmitida envolvendo elementos verbais em conjunto elementos visuais, valendo também para a mensagem com finalidade corretiva.

A mensagem punitiva, que pode ocorrer durante a instrução de um movimento a fim de notificar o que o aluno fez de errado, pode apresentar-se redundante quando traz a mesma informação do feedback intrínseco (por exemplo, o professor dizendo ao aluno: "você não está tocando bem esse trecho", ou, "você errou várias notas durante aquela passagem"). Esse conhecimento de resultado que é redundante com o feedback intrínseco, além de não trazer informações relevantes, pode ser desmotivador e até mesmo irritante a alguns alunos. Como estratégia de estimular o aluno, o professor pode perguntar o que ele achou de seu desempenho 
e, em seguida, apontar os erros indicando formas de corrigi-los, através de dicas e demonstrações de como executar o movimento.

Em conjunto com o feedback extrínseco, deve-se buscar individualmente soluções técnico-interpretativas, desenvolvendo assim uma habilidade em encontrar planos de ação para a execução músico-instrumental. Chiviacowsky e Tani (1997) atentam para a importância de desenvolver o chamado reforço subjetivo, onde o executante desenvolve a sensibilidade de detecção e correção de seus próprios erros, fornecendo subsídios para que continue mantendo seus níveis de resultado em relação às tarefas desempenhadas. Também é importante que desde cedo se desenvolva a consciência corporal (tensão-relaxamento), através de exercícios de respiração e alongamento, assim de flexibilidade do movimento dos segmentos mais envolvidos na execução pianística: braços, mãos e dedos. Também o feedback auditivo, aquele referente aos parâmetros musicais, têm um importante papel no processo de memorização, influenciando na leitura musical e no desempenho das peças estudadas. (Finney e Palmer, 2003).

Outra forma de feedback é a gravação áudio-visual, esta bastante aproveitada na atividade pianística. Utilizando o recurso de feedback visual, o músico pode ver seus padrões de movimento com um maior detalhamento, analisando sua prática visualmente e sonoramente. Esse recurso pode ser usado durante as sessões de prática, a fim de avaliar seu desenvolvimento no processo de estudo, assim como para registrar suas apresentações em público, levando em consideração outras variáveis como a acústica do local.

\section{Métodos de Análise}

Dentre os métodos de medição e avaliação dos movimento descritos neste trabalho estão a cinemetria, a eletromiografia e antropometria.

Através da cinemetria (ou cinematografia) são feitas medições dos movimentos realizados pelo(s) executante(s) através de imagens, registro de trajetórias, decurso de tempo, determinação de curvas de velocidade e de aceleração, entre outras variáveis. Para a captação das imagens, os biomecânicos comumente utilizam sistemas de videografia de alta velocidade, articulando as câmeras em diferentes pontos espaciais, a fim de documentar a cinemática do movimento. Com o auxilio de pontos marcados nos eixos articulares, o gesto pode 
ser digitalizado e reconstruído em duas ou três dimensões. (Allard et al., 1995). Lu e O'connor (1999) destacam que para uma boa avaliação cinemática, é determinante a definição de protocolos experimentais para a colocação dos marcadores. Estes marcadores devem ser posicionados de maneira adequada à estrutura anatômica, eixos articulares, de modo a orientar cada segmento corporal no espaço tridimencional (3D), determinando as variações angulares em cada articulação e respeitando todos os graus de liberdade existentes.

Os sistemas áudio-visuais têm evoluído cada vez mais podendo-se, atualmente, encontrar sistemas de vídeo digitais de alta resolução e alta freqüência a um custo acessível. Entretanto, para uma análise qualitativa que não envolva movimentos muito rápidos, a utilização de uma câmera de vídeo convencional pode atender satisfatoriamente os propósitos da avaliação. Já a análise quantitativa, realizada através da digitalização dos centros articulares do indivíduo, compreende cálculos de grandezas cinéticas e variáveis cinemáticas, o que requer uma instrumentação técnica mais elaborada. (Hall, 1993).

Amadio e Baumann (1990, p.752) apontam alguns dos principais objetivos do procedimento cinemático: “(1) avaliação da técnica para competição, (2) desenvolvimento de técnicas de treinamento, (3) monitoramento de atletas e (4) detecção de talentos esportivos". Considerando-se que o movimento pode apresentar uma grande variabilidade de trajetórias, os indicadores cinemáticos tornam-se de grande importância para a avaliação de fatores como a velocidade dos segmentos e articulações, podendo-se determinar as variações da aceleração do movimento, suas variações angulares, assim como outras variáveis concernentes a meta do movimento. (Amadio et al., 2002).

Outro elemento relevante a ser considerado em qualquer análise biomecânica é o número de tentativas ao se executar um movimento, visto que o grau de proficiência do executante fará com que a cinemática do movimento varie para mais ou para menos, inversamente. É recomendável que sejam feitas outras avaliações depois do experimento-piloto, a fim de ratificar os resultados.

O feedback intrínseco também tem um papel importante no processo de avaliação do movimento, trazendo à investigação informações relevantes acerca do desempenho. O executante que possui uma percepção apurada de seus movimentos pode assinalar possíveis erros técnicos ou perceptivos que ocorreram 
durante a execução, erros que não podem ser apontados em uma simples observação visual.

Através da cinética - campo que estuda o movimento dos corpos e suas forças associadas - pode-se analisar a quantidade de força produzida pelos músculos, quantificando assim qual a força apropriada ou necessária a uma ação específica do movimento. Nesse mesmo tipo de análise, pode-se considerar fatores antropométricos como o peso e as dimensões dos segmentos corporais.

$\mathrm{Na}$ antropometria são obtidas as medidas corporais do indivíduo, usando-se equipamentos como balanças, fita métrica e paquímetros digitais. Essas medidas são utilizadas para outros métodos de análise, como a cinematografia, por exemplo, e são necessárias para a normalização dos dados e personalização dos modelos físico-matemáticos. (Amadio et al., 2002). Cada indivíduo possui uma configuração corporal diferente do outro que devem ser levadas em consideração no processo de aprendizagem de uma habilidade motora.

A eletromiografia (EMG) é um método utilizado para medição de potenciais elétricos de um músculo ou grupo de músculos, através da verificação dos níveis de participação de cada músculo durante a realização do movimento. Através da eletromiografia, é possível identificar-se os músculos que estão sob tensão durante o movimento ou até em estado de "repouso", permitindo assim mapear possíveis fixações musculares desnecessárias ao movimento, através de eletrodos que são colocados sobre a pele (discos) ou diretamente no músculo (agulhas).

\section{Conclusões}

A complexidade do movimento humano, em especial da ação pianística, desperta 0 interesse na investigação sobre o que realmente ocorre no sistema músculo-esquelético. O grande número de variáveis durante um movimento, em função das características específicas de cada segmento corporal e, sobretudo, de cada indivíduo, determina que uma análise de movimentos estruturalmente tão complexos seja acima de tudo objetiva e efetiva.

Atualmente encontram-se disponíveis várias ferramentas para 0 aprimoramento do movimento humano e consciência das estruturas corporais envolvidas na ação. Os métodos de análise e medição biomecânicos permitem uma maior compreensão dos mecanismos internos reguladores e executores do 
movimento através de sua descrição, interpretação e análise. Alguns processos, como a cinemática, levam em consideração fatores como velocidade dos segmentos, trajetórias dos eixos articulares, ações dos membros envolvidos na ação e suas participações para o sucesso do gesto, entre outros aspectos. A eletromiografia pode ser utilizada para verificar níveis de fadiga e níveis de tensão muscular quando da execução de um movimento.

Vale ressaltar a necessidade de que profissionais da área da música se interessem na cooperação interdisciplinar, em especial nas áreas de Anatomia e a Fisiologia, observando o importante papel que a fundamentação científica do aprendizado musical pode trazer através de seu embasando em explicações experimentais do movimento. O conhecimento acerca dos métodos de medição ainda são, hoje em dia, pouco difundido na área da música. Através da análise e interpretação do movimento podem-se definir modelos e protocolos de avaliação, estabelecendo estratégias de ação que auxiliarão o instrumentista a apurar seus padrões de movimento, otimizando assim sua atividade. $\mathrm{Na}$ atividade pianística, existem atualmente poucas pesquisas que trabalham com protocolos de avaliação do movimento, ou até mesmo pesquisas interdisciplinares que tenham conexão com a atividade instrumental.

Esta pesquisa mostrou novas possibilidades de investigação, constatando-se a necessidade de que mais estudos nesse sentido sejam realizados, buscando-se compreender e otimizar cada vez mais a prática instrumental.

\section{Referências bibliográficas:}

ALLARD, P.; STOKES, A. F.; BLANCHI, J. P. Three-dimensional analysis of human movement. Champaign: Human Kinetics, 1995.

AMADIO,. et al. Métodos de medição em biomecânica do esporte: descrição de protocolos para aplicação no centros de excelência esportiva. Revista Brasileira de Biomecânica: v.3, n.4, p. 57-67, 2002.

AMADIO, Alberto C.; BAUMANN, W. Kinetic and Electromyographical analysis of the triple jump. Sport und Buch Strauss: p. 751-752, 1990.

CIARLINI, Myrian; RAFAEL, Maurílio. O Piano. Campina Grande: LIAA, 1994. 
CHIVIACOWSKY, Suzete; TANI, Go. Efeitos da freqüência de conhecimento de resultados na aprendizagem de diferentes programas motores generalizados. Revista Paulista de Educação Física: v.1, n.11, p. 15-26, 1997.

FINNEY, Steven A. ; PALMER, Caroline. Auditory feedback and memory for music performance: Sound evidence for an encoding effect. Memory \& Cognition: v.1, n.31, p. 51-64, 2003.

LU, T-W ; O`CONNOR, J. J. Bone estimation from skin Marker co-ordimates using global optimation with joint constraints. J. Biomechanics: v.32, p. 129-34, 1999.

HALL, Susan. Biomecânica Básica. Traduzido por Giuseppe Taranto. Rio de Janeiro: Guanabara Koogan, 2005.

KAPLAN, José A. Teoria da Aprendizagem Pianística. Porto Alegre: Movimento, 1987.

MAGGIL, Richard A. Aprendizagem Motora: conceitos e aplicações. Tradução de Aracy Mendes da Costa. São Paulo: Edgard Blücher, 2000.

PIEKARZIEVCZ, Luiz E. Efeitos do feedback extrínseco aumentado no processo de aprendizagem de uma habilidade motora fechada. Dissertação de Mestrado, 2004, Universidade Federal do Paraná.

PÓVOAS, Maria B. C. Princípio da Relação e Regulação do Impulso-Movimento. Possíveis Reflexos na Ação Pianística. 236 p. Tese de Doutorado, Mímeo, 1999, Universidade Federal do Rio Grande do Sul.

RASCH, Philip J. Cinesiologia e Anatomia Aplicada. Tradução de Marcio Moacyr de Vasconcelos. Rio de Janeiro: Guanabara Koogan, 1991.

SCHMIDT, Richard A.; WRISBERG, Craig A. Aprendizagem e performance motora: uma abordagem de aprendizagem baseada no problema. Tradução de Ricardo Petersen... [et al]. 2th ed. Porto Alegre: Artmed Editora, 2001. 